\title{
Sensitivity to Kinship: From Electrophysiological Perspective
}

\author{
Xia Zou' ${ }^{1}$, Zhixiong Yan ${ }^{2 *}$ \\ ${ }^{1}$ Guangxi College for Preschool Education, Nanning, China \\ ${ }^{2}$ Bagui Scholar Innovative Team, Guangxi Teachers Education University, Nanning, China \\ Email: *yanzx@gxtc.edu.cn
}

How to cite this paper: Zou, X. and Yan, Z.X. (2017) Sensitivity to Kinship: From Electrophysiological Perspective. Open Journal of Social Sciences, 5, 70-81. https://doi.org/10.4236/jss.2017.52008

Received: January 10, 2017

Accepted: February 5, 2017

Published: February 8, 2017

Copyright (c) 2017 by authors and Scientific Research Publishing Inc. This work is licensed under the Creative Commons Attribution International License (CC BY 4.0).

http://creativecommons.org/licenses/by/4.0/

\begin{abstract}
It is well known that different person have specific psychological meaning to us. We usually feel more positive to intimates (kin) than relatively non-intimate ones (non-kin). However, until recently, the underlying mechanism about kinship remains poorly understood. Thus, we further investigated whether the degree of kinship between a perceiver and a target person leads to the perceiver's specific electrophysiological response. Event-related brain potentials (ERPs) of 22 participants (age: $20.8 \pm 2.13$ ) were observed when changed the degree of kinship (father, uncle, acquaintance) in morally laden scenarios. Our results demonstrated that the amplitudes of neural response varied among kins and acquaintance. Specifically, fronto-central positive activity at $180-230 \mathrm{~ms}$ (P2) and central-parietal late positive activity at $350-500 \mathrm{~ms}$ (LPC) were of larger mean amplitude in response to father than to uncle and acquaintance, which are indicative of intense information processing and sensitivity to a lineal relative in moral cognitive context. Those findings showed direct evidences of consanguineous bias in moral-related contexts, which will provide valuable reference for intervention of tensioned relationship and other related disorders.
\end{abstract}

\section{Keywords}

Kinship Bias, Morally Laden Scenario, P2, N2, LPC, ERPs

\section{Introduction}

Kin selection theory (KST) or inclusive fitness theory refers to more positive attitude or altruistic behavior to kins relative to others, which is naturally seen as a product of biological evolutionary [1]. Prior similar researches provide the evidences that human provides more assistance to kin relative to non-kin [2] [3] [4]. Lieberman and Tooby et al. [5] proposed that the kinship index, $K I_{\mathrm{i}}$ corres- 
ponds to the estimate of genetic relatedness between self and $i$ (each familiar individual) which serves as an index of altruistic behavior to kins. Participants expressed a greater willingness to help siblings and a high level of reciprocal exchange than friends, which are partly responsible for altruistic behaviors [2]. After that, $\mathrm{Lu}$ and Chang [6] examined episodic temporal judgment bias in favor of kin through individuals' subjective temporal estimations of past events. Kaminski and Dridi et al. [7] confirmed that, through visible facial cues, humans are capable of identifying which individual is kinship. Kin detection mechanisms exist in humans and the kinship index presents sibling altruism [5]. All those findings show obvious cognitive and behavior bias to kin relative to non-kin. The electrophysiological evidence is rare except Chen and Qiu et al. [8] who investigated a specific moral dilemma where two relatives (e.g., father and mother) or two strangers buried in debris from a disaster. The participants had to decide whom to rescue first, mother or strangers. The results showed that, compared to strangers, relatives elicited an enhanced evoked potential neural response (P2 and P3), which suggested that relatives had preponderant processing in stimulus evaluation and conflict resolution compared with strangers. Research about kin selection in distant relatives such as grandparents [4] [9], aunts/uncles [10] and cousins [3] were also specifically emphasized.

Taken together, though previous studies focused on kin-serving bias, the category standard is vague, and merely dividing kinship by kin, acquaintance and stranger using anonymous agents [8]. No study has been conducted to systematically investigate the degree of consanguinity. The brain processing mechanism of different kin stimuli and the spatiotemporal features of the degree effect in kin-serving bias remain unclear. Moreover, there is no information on the timing and order of kinship processes bias involved in morally laden visual scenarios, which is a fundamental aspect of social cognition. Therefore, we took the temporal advantage of ERPs to examine the dynamics of the neural processing evoked by the perception of morally laden scenarios in which three kinship of the participant (the parent, uncle and an acquaintance) acted as protagonists. We used the actual name of participant' father as the lineal relative, the actual name of an uncle as the collateral relative and the actual name of an acquaintance as the acquaintance [11]. The research aims to discover the spatiotemporal features about kin-serving bias in morally laden scenarios.

Based on previous ERPs studies [8] [12] [13] [14], we surmised that P2 and LPC or P3 components might be the related indices of stimulus evaluation, motivational significance or mental effort [12] [13] [15] [16]. We hypothesized that individuals show sensitivity or biases to more closely related kin. It would faster and more frequently for participants to decide to rescue closer relatives than non-relatives (specifically, most frequently and fastest for father) and that the rescuing decision would elicit a greater P2 and LPC in response to father compared to uncle and acquaintance. 


\section{Materials and Methods}

\subsection{Participants}

As paid volunteers, 22 undergraduate students ( 10 women, 12 men) aged 19 - 23 years (mean age: $20.8 \pm 2.13$ ), in Guangxi Teachers Education University participated in the experiment. All participants were right-handed, had normal or corrected-to-normal vision, and had no current or past neurological or psychiatric illness. All gave written informed consent before participating.

\subsection{Materials}

We chose eight story segments (187 - 225 Chinese words in length, refer to [17]) and revised the protagonists as the name of participant's father $(\mathrm{r}=0.5)$, uncle $(\mathrm{r}=0.25)$ or an acquaintance $(\mathrm{r}=0)$ according to Hamilton's inclusive fitness theory [1]. The morally laden scenarios we included met the following criteria: 1) were realistic and conceivably might be faced in daily life settings for our sample; 2) contained a high-conflict tradeoff; and 3) reflected harm and care with respect to the protagonists. To validate the scenarios, we asked 50 undergraduate students ( 27 males, 23 females, $20.95 \pm 1.93$ ), drawn from the same population as the experimental sample, to evaluate both the negative emotional intensity and the extent to which degree each scenario portrayed an ethical dilemma on a 7 -point scale $(1=$ not at all, $7=$ extremely strong $)$. A one-way repeated measures analysis of variance (ANOVA) demonstrated that the different scenarios did not differ significantly in the scores of emotional intensity (overall mean $=6.58, \mathrm{SD}=0.87$ ) or the scores of the extent of dilemma (mean = $6.24, \mathrm{SD}=0.53, \mathrm{~F}(7,392)=1.78, \mathrm{p}>0.05$, and $\mathrm{F}(7,392)=1.85, \mathrm{p}>0.05$, respectively).

Experimental materials were presented on a 17-in. computer monitor screen, including the morally laden scenarios, the three types of stimuli (the names of every subject's father, uncle and an acquaintance), and several interpolated displays (e.g., a fixation cross). Target names were displayed in random order in the center of the screen. The size of each name was approximately $1.72 \mathrm{~cm}$ (horizontal) $\times 0.92 \mathrm{~cm}$ (vertical). It should be noted that, for Chinese names, the names of father and uncle, sometimes even an acquaintance may look very similar (e.g., Cheng Jianguo, Cheng Jianzu, Cheng Ziqiang, and may elicit very similar visual response).

\subsection{Procedure}

Subjects were seated in a semi-dark room facing the computer monitor placed $60 \mathrm{~cm}$ from their eyes, and the horizontal and vertical visual angles subtended by the stimuli were below $5^{\circ}$. We instructed participants to keep their eyes fixated on the monitor throughout experimental trials. The total experiment included practice phase (a single scenario and 10 trials, data not included in analysis) and test phase ( 8 scenarios or blocks and 240 trials, 30 trials per block in which 10 trials for each condition, randomized). In each block of the test phase, a written scenario was first presented on the screen. After the subject finished reading the 
scenario, he or she pressed a key, and a plus sign appeared in the center of screen for $300 \mathrm{~ms}$, followed by a blank screen that persisted for $500-800 \mathrm{~ms}$. Then the name of the subject's father, uncle or acquaintance was presented for $500 \mathrm{~ms}$. The subject's task then was to decide as quickly as possible whether or not to rescue the person in the given scenario. Participants showed their decision by pressing the corresponding key ("Z" to represent rescue and "?" to represent do not rescue) on the keyboard. After the answer key was pressed, there was an intertrial interval of $1000 \mathrm{~ms}$ with a blank screen. The next trial started with a plus sign for $300 \mathrm{~ms}$, then another name and so on. Each block contained 30 trials (each name appeared in 10 trials), and the subject took breaks between blocks. The participants' choices (rescue, don't rescue), reaction times (interval between presentation of the target name and the participant's response) and ERP while viewing the names and making the decision were recording. See Figure 1 for a schematic diagram of the structure of the experimental trials.

\subsection{ERP Recordings}

For each participant, during each decision trial, we recorded electroencephalograms (EEGs) continuously from 64-scalp silver/silver-chloride electrodes located according to the international 10 - 20 system. All electrodes were referenced to an electrode at the left mastoid and re-referenced off-line to another electrode at the contralateral mastoid. The horizontal electrooculogram (EOG) was recorded bipolarly from two electrodes placed $1.5 \mathrm{~cm}$ lateral to the left and right outer canthi, and the vertical EOG from electrodes below and above the left eye. The impedance for each electrode was kept below $5 \mathrm{k} \Omega$. EEG signals were amplified (half-amplitude band pass $0.05-70 \mathrm{~Hz}$ ) and digitized at a sampling rate of $250 \mathrm{~Hz}$.

The evoked responses (ERPs) in each stimulus condition (Father, Uncle and Acquaintance) were averaged separately off-line with averaging epochs beginning $100 \mathrm{~ms}$ prior to presentation of the name stimulus onset and ending $500 \mathrm{~ms}$ after name stimulus onset (i.e., stimulus offset). Trials contaminated by eye blinks, eye movements, or muscle potentials exceeding $\pm 50 \mu \mathrm{V}$ were excluded from analyses. In order to test lateralization, the following 15 electrode sites were selected for statistical analysis: five left sites (F3, FC3, C3, CP3, P3; five midline sites (Fz, FCz, Cz, CPz, Pz); and five right sites (F4, FC4, C4, CP4, P4). Latencies

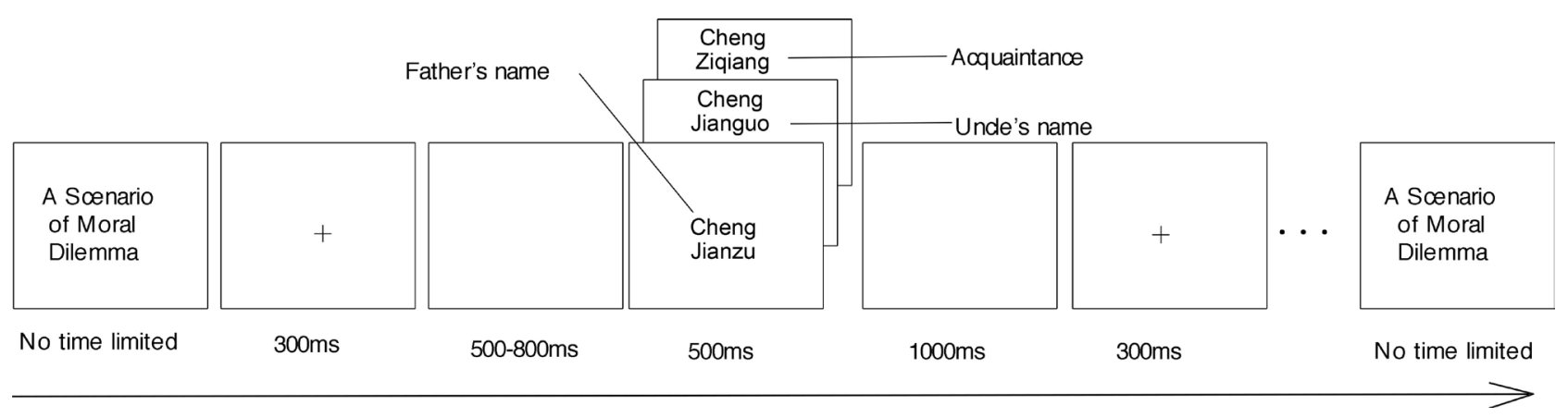

Figure 1. The process of the experiment. 
and peak amplitudes of $\mathrm{N} 1(90-130 \mathrm{~ms})$ and the mean amplitude of the P2 $(180-230 \mathrm{~ms}), \mathrm{N} 2(290-340 \mathrm{~ms})$ and LPC (350 - $400 \mathrm{~ms}, 400-450 \mathrm{~ms}, 450$ $500 \mathrm{~ms}$ ) components were measured separately.

\section{Results}

\subsection{Behavioral Data}

The frequencies of choosing to rescue the various protagonists (Father 89\%; Uncle $63 \%$; Acquaintance $11 \%$ respectively) were significantly different $\left(\chi^{2}>100, p<\right.$ $0.001)$. Therefore, the choice frequency favored the most closely related target person, as predicted.

Analyzed using one-way analysis of variance (ANOVA), decision latencies differed globally across the three name stimuli, $F(2,42)=7.34, p<0.01$. Post hoc comparisons ( $t$ values $=1.79-1.83$, all $p<0.05$, respectively) showed that the responses to fathers $(445.15 \pm 94.34)$ were faster than those to uncles $(542.21 \pm$ $61.55)$ or to acquaintances ( $551.91 \pm 66.45)$, but latencies did not differ between uncles and acquaintances. Latency outcomes were both consistent with hypothesis and with the choice outcomes.

These results indicate that, on a behavioral level, degree of kinship affected choices to rescue or not, that is, that rescue decisions were bias to favor closer kinship relations. Note that all other test conditions were balanced except for the kinship relation portrayed (i.e., kinship varied within common scenarios).

\subsection{ERP Data}

ERPs in response to names were characterized by a negative wave at $90-130 \mathrm{~ms}$ (N1) and a positive deflection at $180-230 \mathrm{~ms}$ (P2) over the frontal-central area. These were followed by a negative wave at $290-340 \mathrm{~ms}$ (N2) over the frontal region and a long-latency positivity at $350-500 \mathrm{~ms}$ (LPC) over the central and parietal sites (see Figure 2 and Figure 3).

Three-way repeated measures analysis of variance (ANOVAs) on peak amplitudes of different ERP components were conducted;, independent variables included stimulus type (Father, Uncle and Acquaintance), laterality (left, midline and right sites) and causality (front, front-central, central, central-parietal, and parietal sites). The degrees of freedom of the F-ratio were corrected according to the Greenhouse-Geisser method.

\subsubsection{N1 (90 - $130 \mathrm{~ms})$}

ANOVAs of the N1 amplitude and latency demonstrated no significant effects $[F(2,42)=1.08, p>0.05]$.

\subsubsection{P2 (180 - $230 \mathrm{~ms}$ )}

ANOVA on the P2 mean amplitude at $180-230 \mathrm{~ms}$ showed a significant main effect of kinship $\left[F(2,42)=5.62, p<0.01, \eta^{2}=0.21\right]$. Post hoc analyses further confirmed that the $\mathrm{P} 2$ mean amplitude tended to be larger (approaching significance) to Father than to Uncle stimuli $\left[F(1,21)=3.98, p=0.06, \eta^{2}=0.16\right]$, significantly larger to Father than to Acquaintance $[F(1,21)=10.55, p<0.01$, 
$\left.\eta^{2}=0.33\right]$. However, the $\mathrm{P} 2$ mean amplitudes were not significantly different $[F$ $\left.(1,21)=2.34, p=0.14, \eta^{2}=0.10\right]$ between Uncle to Acquaintance conditions.

\subsubsection{N2 (290 - $340 \mathrm{~ms})$}

ANOVAs on the N2 average amplitudes at $290-340 \mathrm{~ms}$ showed only a significant interaction between kinship and causality $\left[F(8,168)=3.97, p<0.05, \eta^{2}=\right.$ $0.16]$. The differences of $\mathrm{N} 2$ mean amplitudes among kinship categories was significant at central-parietal $[F(2,42)=3.23, p<0.05]$ and parietal sites $[F(2,42)=$ $5.89, p<0.01]$. The main effect of kinship type was not significant on $\mathrm{N} 2$ mean amplitude $\left[F(2,42)=2.38, p=0.13, \eta^{2}=0.10\right]$.

\subsubsection{LPC ( 350 - $400 \mathrm{~ms})$}

ANOVAs of the LPC average amplitudes at $350-400 \mathrm{~ms}$ showed a significant effect of kinship $\left[F(2,42)=8.87, p<0.01, \eta^{2}=0.30\right]$, as the LPC at $350-400 \mathrm{~ms}$
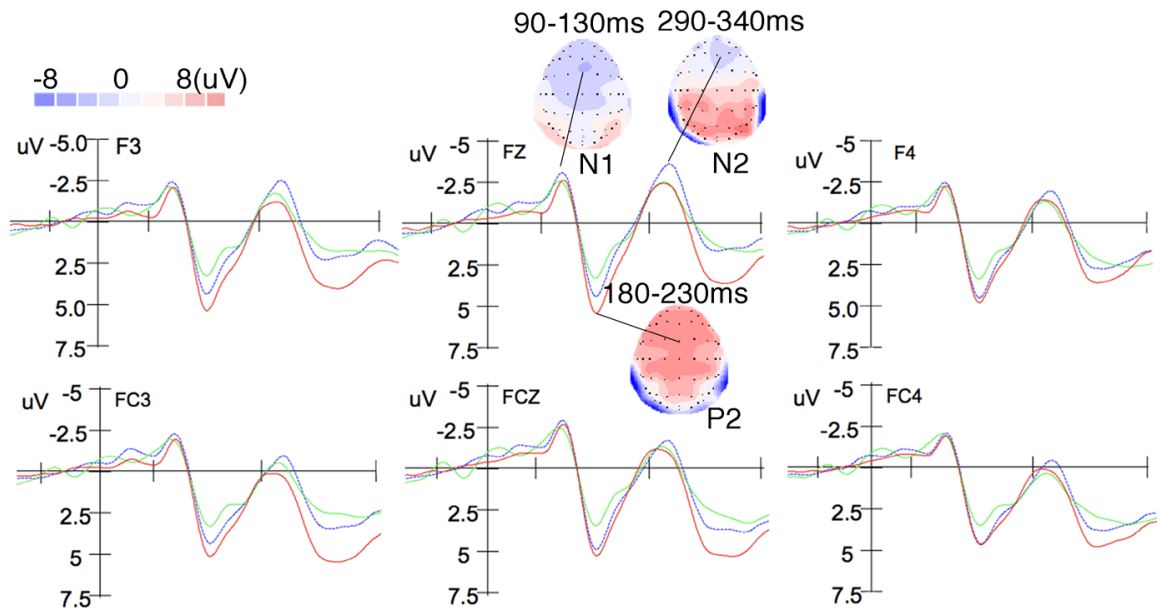

uV -5 T FC4

uV -5 T $\mathrm{C3}$$$
\text { uV }-5 \text { T } C Z
$$
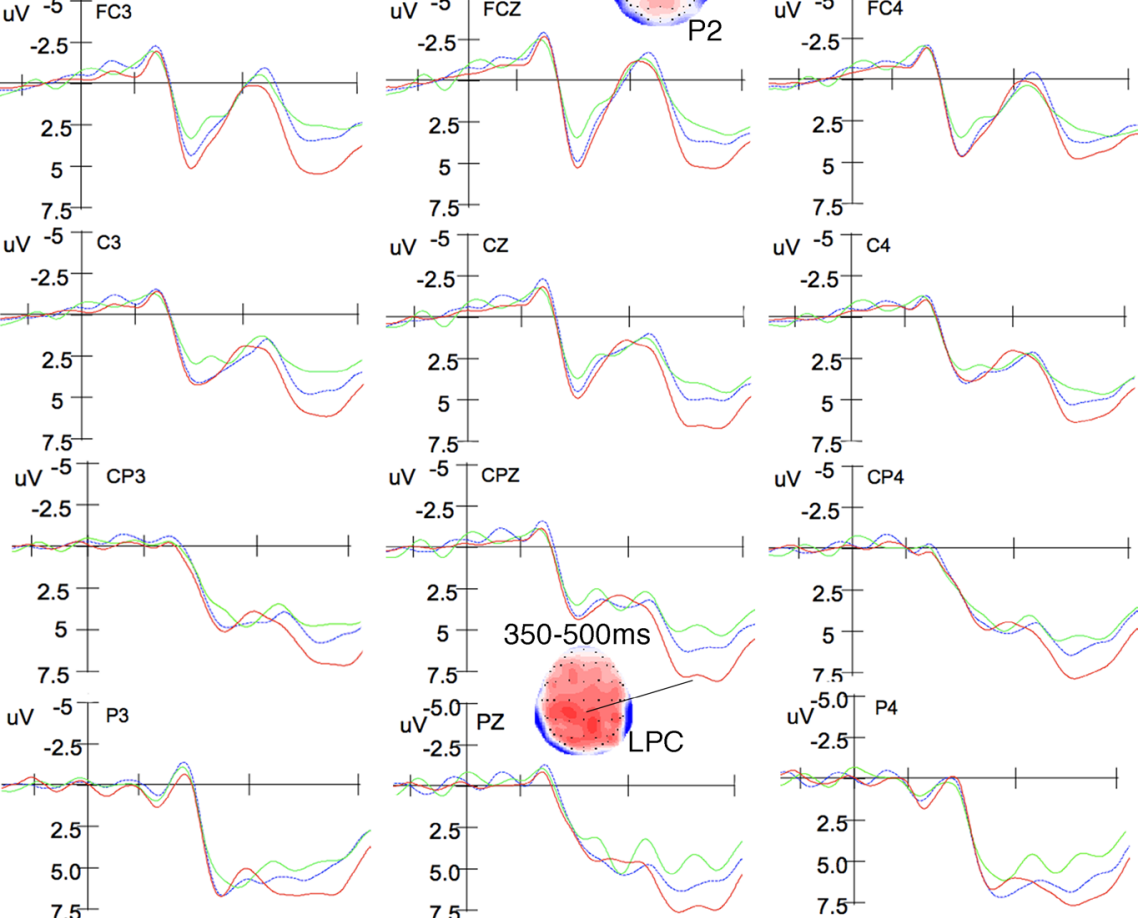

$$
7.5
$$

uV -5 T $\mathrm{C} 4$
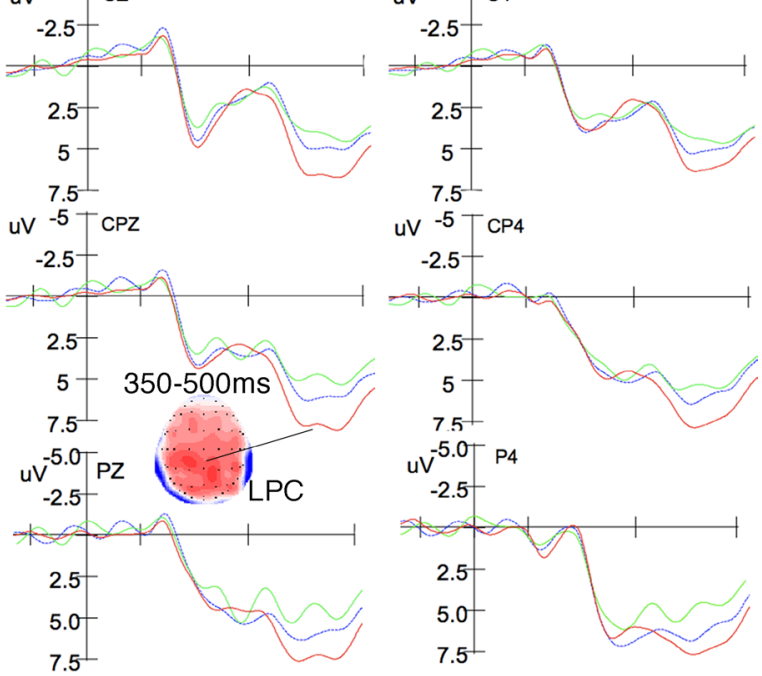

$u \mathrm{~V}^{-5.0} \mathrm{P} 4$
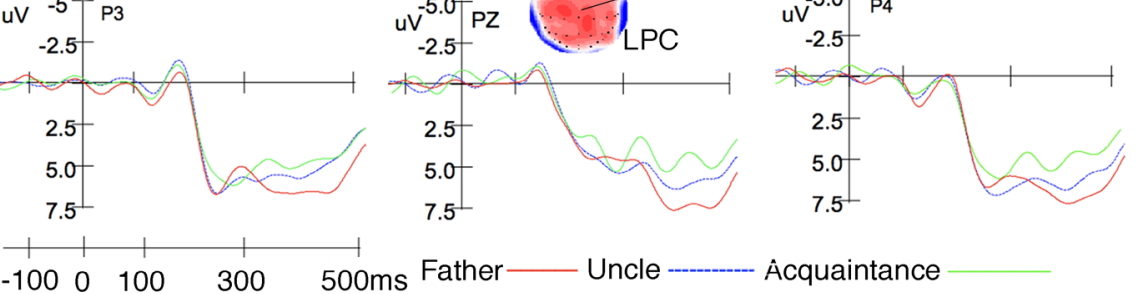

Father

Uncle

Âcquaintance

Figure 2. ERPs to name stimuli recorded at F3, FZ, F4, FC3, FCZ, FC4, C3, CZ, C4, CP3, $\mathrm{CPZ}, \mathrm{CP} 4, \mathrm{P} 3, \mathrm{PZ}$ and P4 for Father(red lines), Uncle (blue lines) and Kith or Acquaintance (green lines). The voltage topographies illustrate the scalp distribution of each ERP component. 


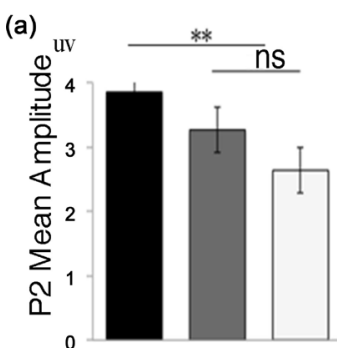

(d)

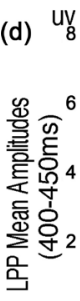

(b)

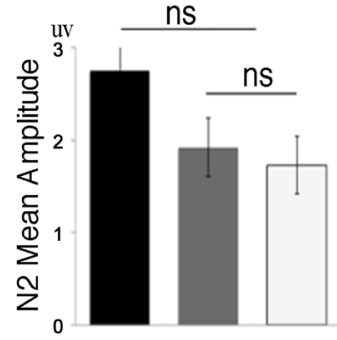

(e)

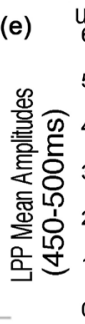

(c)

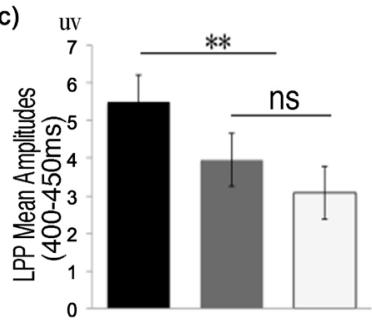

(f)

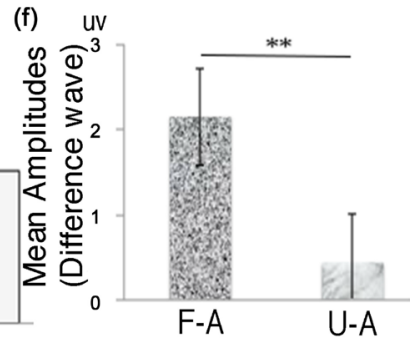

- Father $=$ Uncle $\square$ Acquaintance

Figure 3. Bar graphs of average amplitudes during Father, Uncle and Acquaintance (Kith) conditions in the P2, N2, LPC (350 - 400, 400 - 450, 450 - 500) time window ((a)-(e)) and average amplitude of difference wave (400 - $500 \mathrm{~ms})$ (f). "***" means the difference is significant at 0.01 level, "ns" means no significant difference, "F-K" means Father minus Kith, "U-K" means Uncle minus Kith.

was of larger mean amplitude to Father than to Uncle $[F(1,21)=10.62, p<0.01$, $\left.\eta^{2}=0.34\right]$, and to Father to Acquaintance $\left[F(1,21)=15.75, p<0.01, \eta^{2}=0.43\right]$, but not to Uncle than to Acquaintance $\left[F(1,21)=1.82, p=0.19, \eta^{2}=0.08\right]$. Figure 3 illustrates the effect.

\subsubsection{LPC ( 400 - $450 \mathrm{~ms})$}

ANOVAs of the LPC average amplitudes at $400-450 \mathrm{~ms}$ showed a significant effect of kinship type $\left[F(2,42)=12.45, p<0.01, \eta^{2}=0.37\right]$, as can be seen in Figure 3 . Post hoc comparisons showed that Father elicited a more positive ERP deflection than did Uncle $\left[F(1,21)=22.02, p<0.01, \eta^{2}=0.51\right]$ and Acquaintance $[F(1,21)=$ 20.45, $\left.p<0.01, \eta^{2}=0.49\right]$, but the difference between Uncle and Acquaintance did not show any significant difference $\left[F(1,21)=1.11, p=0.30, \eta^{2}=0.05\right]$.

\subsubsection{LPC ( 450 - $500 \mathrm{~ms})$}

ANOVAs of the LPC average amplitudes at $450-500 \mathrm{~ms}$ also showed a significant effect of kinship type $\left[F(2,42)=4.98, p<0.05, \eta^{2}=0.19\right]$. See Figure 3 . Post hoc comparisons showed that Father elicited a more positive ERP deflection than did Uncle $\left[F(1,21)=8.07, p<0.01, \eta^{2}=0.28\right]$ and Acquaintance $[F(1,21)=$ 8.03, $\left.p<0.01, \eta^{2}=0.28\right]$, but the difference between Uncle and Acquaintance still did not show any significant difference $\left[F(1,21)=0.15, p=0.70, \eta^{2}=0.01\right]$.

\section{Discussion}

To determine the timing course and order priority among different kinship, we used ERPs to examine the temporal dynamics of the kin processing evoked by the perception of visual morally laden scenarios. After verifying behaviorally the existence of kin-serving bias, specifically, lineal relative (Father) do have advan- 
tages over other relative (Uncle) and acquaintance. We also identified Such an bias can be found in both early (P2) and late processing stages (N2, LPC) in the brain, reflected by different ERP components and brain regions. More specific, our ERP results demonstrated increased P2 and LPC mean amplitudes to father stimuli, compared to those for Uncle and Acquaintance. Several previous researches found similar consistent results, such that human commonly showed kinship bias, automatically value lineal lives over other relatives or kith for the former may improve more inclusive fitness [1] [8] [18] [19].

In the time course of cognitive process, lineal relative was significantly distinguished from other relative or kith in three main time periods (i.e., from 180 to $230 \mathrm{~ms}$, from 290 to $340 \mathrm{~ms}$ and from 350 to $500 \mathrm{~ms}$ poststimulus, see Figure 2). The specific ERP components elicited by three types of name include an early automatic intentional salience (P2) and late positive potentials that are associated with affective arousal and appraisal of the stimuli, respectively [20]. We will elaborate in detail as follows.

On the early visual processing, N1 $(90-130 \mathrm{~ms})$ was similar in the three conditions. It was suggested that $\mathrm{N} 1$ component was related to early visual attention [21]. Consistent with this, there is no significant difference in N1 component between the three name stimuli, which may show that all characters of the name stimuli might be approximately equal in word size, length and complexity. A first different fronto-central P2 (180 to $230 \mathrm{~ms}$ ) activity was elicited in three name conditions in which Father stimuli elicited larger P2 amplitudes than that of Uncle or Kith, which is consistent with the previous findings [22] [23]. It has been indicated that frontal P2 activity is indicative of rapid detection of stimulus features, sensitive to attention recruitment [24] [25] and initiation of decision-making [13] [26] [27]. In present study, the results showed that Father stimuli had advantages in mental effort and priming decision-making relative to that of Uncle and Acquaintance at early stage.

After 290 ms time window, Father stimulus activated weaker N2 component in central-parietal position and greater LPC than other stimuli. Based on previous studies, decreased N2 may correlate with conflict monitoring of kin detection [28] [29], and influence by familiarity [30], self- [31], or beloved faces [32]. Our results showed that there is no significantly difference of familiarity among Father, Uncle and Kith, but only in the central-parietal region, the trend of difference is statistically significance (see Figure 2). That may be experimental material, previous research adopted face images, but not Chinese characters stimuli as in present investigation, result in this difference. In our research, the kinship bias may be reflected in this time phasing, but refined difference will move to LPC component.

A notable late LPC ( 350 - $400 \mathrm{~ms}, 400$ - $450 \mathrm{~ms}, 450$ - $500 \mathrm{~ms})$ was elicited in parietal sites by all three conditions. Father stimuli elicited a more positive ERP deflection than did Uncle and Acquaintance stimuli between 350 to $500 \mathrm{~ms}$ post-stimulus, and the trend lessened near $450-500 \mathrm{~ms}$. Previous findings indicated that LPC or P3 was highly sensitive to the process of stimulus evaluation, 
response execution [33] and motivational significance [16]. Wu and Yang et al. [28] suggested that LPC may reflect self-referential processing in kin detection. Those findings also provided considerable insight for dilemma interference [15] [34], which reflect conflict resolution processes [35]. Based on previous studies, we suggest that the enlarged LPC to Father may reflect differences between the processes of lineal relative and Uncle or Kith. Although both Father and Uncle or Kith stimuli were targets for judgments, more extensive evaluation could be applied to the Father stimuli because participants had a more positive and valued stereotype for them than for other stimuli, which may also suggest that one's father, as a lineal kin most closely related to one's self, would be processed more fully and comprehensively than other kin and acquaintances who are far from one's self.

More interestingly, there is an obvious trend of degree effect. The order of kinship in the present research is Father, Uncle and Kith. Moreover, the pairwise amplitude differences F-K (Father minus Kith) is greater than U-A (Uncle minus Kith) and mainly pronounced at right central and parietal sites at LPC processing stages (see Figure 4), As previous fMRI studies have shown that moral judgment modulates neural activities in pSTS [36] and ventromedial prefrontal cortex (vmPFC) [37] [38], which suggest that affective processes precede cognitive evaluative processes. Our results indicated that the right central and parietal area (see Figure 4) might mainly relate with kin-serving bias by perception of morally laden scenarios [8]. However, it should be stressed that ERPs technology does not have superiority in spatial resolution. The brain areas reflected in ERP activity are only tentative and approximate, which means ERP localizations should be considered with caution.

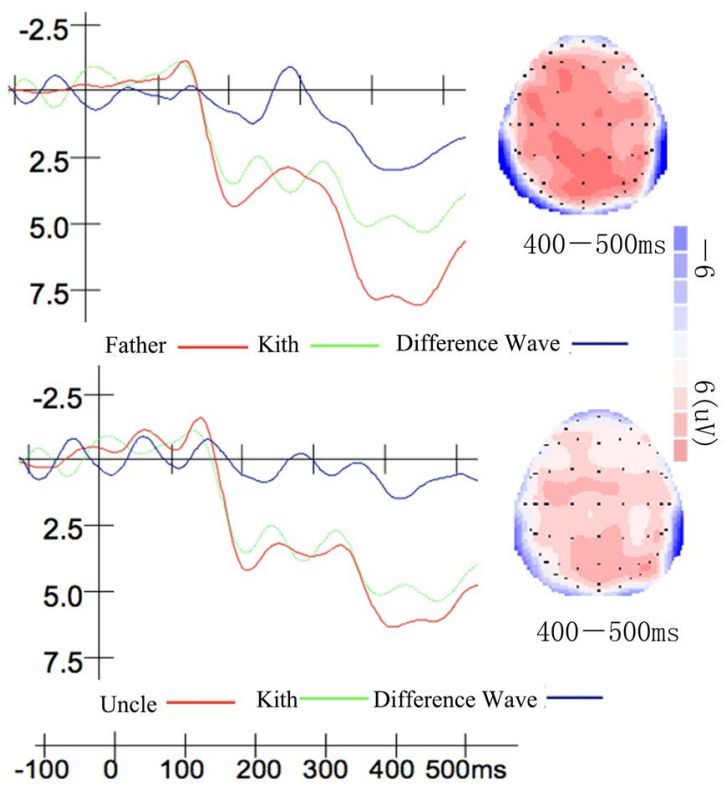

Figure 4. Grand average ERP to Father, Uncle, Kith and the difference wave [Father minus Kith (above), Uncle minus Kith (below)] at CPZ. Topographical maps of the voltage amplitudes for the difference wave [Father minus Kith (Above), Uncle minus Kith (Below)] in $400-500 \mathrm{~ms}$ time window. 
However, several limitations of the present study have to be acknowledged. One limitation of the current study is that we only adapted three names (Father, Uncle and Acquaintance) as kinship stimuli. Thus, many repetitions of the stimulus might be unavoidable, which may raise some doubt about whether subjects really make decisions every time or just repeat the same decision. Specifically, we set up scenarios just to provide an abundant judgmental situation for participants, and not aim to contrast with other non-moral judgment as control scenarios, which need to be emphasized in the future studies.

\section{Conclusion}

Our results provided correlated behavioral and electrophysiological evidence for the existence of kinship bias in the context of moral dilemma judgments. P2, N2 and LPC component may play sensitive indices to discriminate different kinship or stranger, which reflected psychological significance to lineal relative compared with other relatives or acquaintances. These findings may provide insights for relationship modulation or cognitive intervention among rebellious adolescents.

\section{Acknowledgements}

We thank Kevin A. Stein from Southern Utah University for editing English.

\section{Foundation}

This work was supported grants from The Natural Science Foundation of China (NSFC 31660277), Guangxi Natural Science Foundation Program (2016GXNSF459, 2015GXNSFBA139136), Scientific Research Projects in Guangxi Universities (KY2015ZD078).

\section{References}

[1] Hamilton, W.D. (1964) The Genetical Evolution of Social Behaviour. I, II. Journal of Theoretical Biology, 7, 17-52. https://doi.org/10.1016/0022-5193(64)90039-6

[2] Stewart-Williams, S. (2007) Altruism among Kin vs. Nonkin: Effects of Cost of Help and Reciprocal Exchange. Evolution and Human Behavior, 28, 193-198.

https://doi.org/10.1016/j.evolhumbehav.2007.01.002

[3] Jeon, J. and Buss, D.M. (2007) Altruism towards Cousins. Proceedings of the Royal Society B, 274, 1181-1187. https://doi.org/10.1098/rspb.2006.0366

[4] Michalski, R.L. and Shackelford, T.K. (2005) Grandparental Investment as a Function of Relational Uncertainty and Emotional Closeness with Parents. Human Nature, 16, 293-305. https://doi.org/10.1007/s12110-005-1012-5

[5] Lieberman, D., Tooby, J. and Cosmides, L. (2007) The Architecture of Human Kin Detection. Nature, 445, 727-731. https://doi.org/10.1038/nature05510

[6] Lu, H.J. and Chang, L. (2009) Kinship Effect on Subjective Temporal Distance of Autobiographical Memory. Personality and Individual Differences, 47, 595-598. https://doi.org/10.1016/j.paid.2009.05.014

[7] Kaminski, G., Dridi, S., Graff, C. and Gentaz, E. (2009) Human Ability to Detect Kinship in Strangers' Faces: Effects of the Degree of Relatedness. Proceedings of the 
Royal Society B, 276, 3193-3200. https://doi.org/10.1098/rspb.2009.0677

[8] Chen, P., Qiu, J., Li, H. and Zhang, Q. (2009) Spatiotemporal Cortical Activation Underlying Dilemma Decision-Making: An Event-Related Potential Study. Biological Psychology, 82, 111-115. https://doi.org/10.1016/j.biopsycho.2009.06.007

[9] Pollet, T.V., Nettle, D. and Nelissen, M. (2007) Maternal Grandmothers Do Go the Extra Mile: Factoring Distance and Lineage into Differential Contact with Grandchildren. Evolutionary Psychology, 5, 832-843. https://doi.org/10.1177/147470490700500412

[10] Gaulin, S.J.C., McBurney, D.H. and Brakeman-Wartell, S.L. (1997) Matrilateral Biases in the Investment of Aunts and Uncles: A Consequence and Measure of Paternity Uncertainty. Human Nature, 8, 139-151. https://doi.org/10.1007/s12110-997-1008-4

[11] Han Mai, Z.J.J. (2003) Experimental Research on the Structure of Chinese Relation Concepts. Journal of Guangzhou University (Social Science Edition), 2, 55-62.

[12] Lindholm, E. and Koriath, J.J. (1985) Analysis of Multiple Event Related Potential Components in a Tone Discrimination Task. International Journal of Psychophysiology, 3, 121-129. https://doi.org/10.1016/0167-8760(85)90032-7

[13] Potts, G.F. (2004) An ERP Index of Task Relevance Evaluation of Visual Stimuli. Brain and Cognition, 56, 5-13. https://doi.org/10.1016/j.bandc.2004.03.006

[14] Yoder, K.J. and Decety, J. (2014) Spatiotemporal Neural Dynamics of Moral Judgment: A High-Density ERP Study. Neuropsychologia, 60, 39-45.

https://doi.org/10.1016/j.neuropsychologia.2014.05.022

[15] Ila, A.B. and Polich, J. (1999) P300 and Response Time from a Manual Stroop Task. Clinical Neurophysiology, 110, 367-373. https://doi.org/10.1016/S0168-5597(98)00053-7

[16] Nieuwenhuis, S., Aston-Jones, G. and Cohen, J.D. (2005) Decision Making, the P3, and the Locus Coeruleus-Norepinephrine System. Psychological Bulletin, 131, 510532. https://doi.org/10.1037/0033-2909.131.4.510

[17] Greene, J. (2003) From Neural "Is" to Moral "Ought": What Are the Moral Implications of Neuroscientific Moral Psychology? Nature Reviews Neuroscience, 4, 846 850. https://doi.org/10.1038/nrn1224

[18] Cikara, M., Farnsworth, R.A., Harris, L.T. and Fiske, S.T. (2010) On the Wrong Side of the Trolley Track: Neural Correlates of Relative Social Valuation. Social Cognitive and Affective Neuroscience, 5, 404-413. https://doi.org/10.1093/scan/nsq011

[19] Johnson, J.D., Simmons, C.H., Jordav, A. and Maclean, L. (2002) Rodney King and OJ Revisited: The Impact of Race and Defendant Empathy Induction on Judicial Decisions. Journal of Applied Social Psychology, 32, 1208-1223. https://doi.org/10.1111/j.1559-1816.2002.tb01432.x

[20] Cheng, Y., Hung, A.-Y. and Decety, J. (2012) Dissociation between Affective Sharing and Emotion Understanding in Juvenile Psychopaths. Development and Psychopathology, 24, 623-636. https://doi.org/10.1017/S095457941200020X

[21] Vogel, E.K. and Luck, S.J. (2000) The Visual N1 Component as an Index of a Discrimination Process. Psychophysiology, 37, 190-203. https://doi.org/10.1111/1469-8986.3720190

[22] Fan, Y. and Han, S. (2008) Temporal Dynamic of Neural Mechanisms Involved in Empathy for Pain: An Event-Related Brain Potential Study. Neuropsychologia, 46, 160-173. https://doi.org/10.1016/j.neuropsychologia.2007.07.023

[23] Li, W. and Han, S. (2010) Perspective Taking Modulates Event-Related Potentials to Perceived Pain. Neuroscience Letters, 469, 328-332. 
https://doi.org/10.1016/j.neulet.2009.12.021

[24] Karayanidis, F. and Michie, P. (1996) Frontal Processing Negativity in a Visual Selective Attention Task. Electroencephalography and Clinical Neurophysiology, 99, 38-56. https://doi.org/10.1016/0921-884X(96)95116-4

[25] Thorpe, S., Fize, D. and Marlot, C. (1996) Speed of Processing in the Human Visual System. Nature, 381, 520-522. https://doi.org/10.1038/381520a0

[26] Yuejia, L. and Parasuraman, R. (2001) The Early ERP Effects Reflect Neural Activity in Spatial Scale of Visual Attention. Acta Psychologica Sinica, 33, 385-389.

[27] Gao, W., Wei, J., Peng, X. and Luo, Y. (2003) Differential Visual Attention Scales Directed by Location versus Semantic Cue. Space Medicine \& Medical Engineering, 16, 14-18.

[28] Wu, H., Yang, S., Sun, S. and Liu, C. (2013) The Male Advantage in Child Facial Resemblance Detection: Behavioral and ERP Evidence. Social Neuroscience, 8, 555567. https://doi.org/10.1080/17470919.2013.835279

[29] Yeung, N., Botvinick, M.M. and Cohen, J.D. (2004) The Neural Basis of Error Detection: Conflict Monitoring and the Error-Related Negativity. Psychological Review, 111, 931-959. https://doi.org/10.1037/0033-295X.111.4.931

[30] Nessler, D., Mecklinger, A. and Penney, T.B. (2005) Perceptual Fluency, Semantic Familiarity and Recognition-Related Familiarity: An Electrophysiological Exploration. Cognitive Brain Research, 22, 265-288. https://doi.org/10.1016/j.cogbrainres.2004.03.023

[31] Sui, J., Liu, C.H. and Han, S. (2009) Cultural Difference in Neural Mechanisms of Self-Recognition. Society for Neuroscience, 4, 402-411. https://doi.org/10.1080/17470910802674825

[32] Langeslag, S.J., Jansma, B.M., Franken, I.H. and Van Strien, J.W. (2007) EventRelated Potential Responses to Love-Related Facial Stimuli. Biological Psychology, 76, 109-115. https://doi.org/10.1016/j.biopsycho.2007.06.007

[33] Duncan-Johnson, C.C. and Kopell, B.S. (1981) The Stroop Effect: Brain Potentials Localize the Source of Interference. Science, 214, 938-940. https://doi.org/10.1126/science.7302571

[34] Donchin, E. and Coles, M.G. (1988) Is the P300 Component a Manifestation of Context Updating? Behavioral and Brain Sciences, 11, 357-374. https://doi.org/10.1017/S0140525X00058027

[35] West, R. and Alain, C. (1999) Event-Related Neural Activity Associated with the Stroop Task. Cognitive Brain Research, 8, 157-164. https://doi.org/10.1016/S0926-6410(99)00017-8

[36] Decety, J. and Cacioppo, S. (2012) The Speed of Morality: A High-Density Electrical Neuroimaging Study. Journal of Neurophysiology, 108, 3068-3072. https://doi.org/10.1152/jn.00473.2012

[37] Koenigs, M., Young, L., Adolphs, R. and Tranel, D. (2007) Damage to the Prefrontal Cortex Increases Utilitarian Moral Judgements. Nature, 446, 908-911. https://doi.org/10.1038/nature05631

[38] Thomas, B.C., Croft, K.E. and Tranel, D. (2011) Harming Kin to Save Strangers: Further Evidence for Abnormally Utilitarian Moral Judgments after Ventromedial Prefrontal Damage. Journal of Cognitive Neuroscience, 23, 2166-2176. https://doi.org/10.1162/jocn.2010.21591 
Submit or recommend next manuscript to SCIRP and we will provide best service for you:

Accepting pre-submission inquiries through Email, Facebook, LinkedIn, Twitter, etc. A wide selection of journals (inclusive of 9 subjects, more than 200 journals)

Providing 24-hour high-quality service

User-friendly online submission system

Fair and swift peer-review system

Efficient typesetting and proofreading procedure

Display of the result of downloads and visits, as well as the number of cited articles Maximum dissemination of your research work

Submit your manuscript at: http://papersubmission.scirp.org/

Or contact jss@scirp.org 